\title{
The distribution of the doped holes in $\mathrm{La}_{2-x} \mathrm{Sr}_{x} \mathrm{Cu}_{1-y} \mathrm{Ru}_{y} \mathrm{O}_{4-\delta}$
}

\author{
Z. Hu ${ }^{\mathrm{a}, \mathrm{d}, *}$, M.S. Golden ${ }^{\mathrm{b}}$, S.G. Ebbinghaus ${ }^{\mathrm{c}}$, M. Knupfer ${ }^{\mathrm{a}}$, J. Fink ${ }^{\mathrm{a}}$, \\ F.M.F. de Groot $^{\mathrm{e}}$, G. Kaindl ${ }^{\mathrm{f}}$ \\ a Institute for Solid State Research, IFW Dresden, P.O. Box 270016, 01171 Dresden, Germany \\ ${ }^{\mathrm{b}}$ Van der Waals-Zeeman Institute, University of Amsterdam, Valckenierstraat 65, 1018 XE Amsterdam, The Netherlands \\ ${ }^{\mathrm{c}}$ Lehrstuhl für Festkörperchemie, Institut für Physik, Universität Augsburg, Universitätsstraße 1, 86159 Augsburg, Germany \\ d II. Physikalisches Institut, Universität zu Köln, Zülpicher Str. 77, 50937 Köln, Germany \\ ${ }^{\mathrm{e}}$ Department of Inorganic Chemistry and Catalysis, Utrecht University, 3584 CA Utrecht, The Netherlands \\ ${ }^{\mathrm{f}}$ Institut für Experimentalphysik, Freie Universität Berlin, Arnimallee 14, 14195 Berlin-Dahlem, Germany
}

Received 21 February 2002

\begin{abstract}
We present a systematic study of the perovskite-related system $\mathrm{La}_{2-x} \mathrm{Sr}_{x} \mathrm{Cu}_{1-y} \mathrm{Ru}_{y} \mathrm{O}_{4-\delta}$ using $\mathrm{Cu} \mathrm{L}_{2,3}, \mathrm{Ru} \mathrm{L}_{2,3}$, and O K X-ray absorption spectroscopy (XAS), magnetic and electrical measurements. This system can be regarded as hole-doped via substitution of $\mathrm{La}$ by $\mathrm{Sr}$ and to be electron-doped via substitution of $\mathrm{Ru}$ by $\mathrm{Cu}$, and thus the question as to the distribution of the charge carriers and the interaction between $\mathrm{Cu}$ and $\mathrm{Ru}$ ions are central to our understanding of these novel systems. The comparison of the experimental data with the crystal-field-multiplet calculations shows clearly that the charge balance for $x / 2 y>1$ is predominantly achieved by an increase of the Ru valence from $\mathrm{Ru}(\mathrm{IV})$ to $\mathrm{Ru}(\mathrm{V})$, while $\mathrm{Cu}$ remains in the $\mathrm{Cu}(\mathrm{II})$ oxidation state. (C) 2002 Elsevier Science B.V. All rights reserved.
\end{abstract}

PACS: 78.70.Dm; 71.28.+d; 79.60

\section{Introduction}

The discovery of high-temperature superconductors (HTSs) [1] has initiated a large number of studies on the system $\mathrm{La}_{2-x} \mathrm{Sr}_{x} \mathrm{CuO}_{4}$, which has the simplest crystal structure among the variety of high-temperature superconductors known today. The parent, unsubstituted compound $\mathrm{La}_{2} \mathrm{CuO}_{4}$ is an antiferromagnetic insulator. Upon Sr-substitu-

\footnotetext{
${ }^{*}$ Corresponding author. Fax: +49-221-470-5178.

E-mail address: zhiwei@ph2.uni-koeln.de (Z. Hu).
}

tion it becomes superconducting with a maximum value of $T_{\mathrm{c}}$ for $x=0.15$ [2]. At higher doping superconductivity disappears again and $\mathrm{La}_{2-x}$ $\mathrm{Sr}_{x} \mathrm{CuO}_{4}$ shows a normal metallic behavior [2]. This has lead to further extensive research of the consequences of substituting the $\mathrm{La}$ or $\mathrm{Cu}$ atoms by other metals.

Recently, superconductivity was also found in the system $\mathrm{Sr}_{2} \mathrm{RuO}_{4}$ at rather low temperatures $\left(T_{\mathrm{c}} \approx 1 \mathrm{~K}\right)[3] . \mathrm{Sr}_{2} \mathrm{RuO}_{4}$ is the first non-copper-oxide superconductor with the same $\mathrm{K}_{2} \mathrm{NiF}_{4}$-type structure as $\mathrm{La}_{2-x} \mathrm{Sr}_{x} \mathrm{CuO}_{4}$. Very little is known about 
other members of the $\mathrm{La}_{2-x} \mathrm{Sr}_{x} \mathrm{Cu}_{1-y} \mathrm{Ru}_{y} \mathrm{O}_{4-\delta}$ system [4-6], which can be considered to be hole-doped via substitution of $\mathrm{La}$ by $\mathrm{Sr}$ and electron-doped by the substitution of $\mathrm{Ru}$ for $\mathrm{Cu}$. Two previous studies $[7,8]$ indicate that single phase $\mathrm{La}_{2-x} \mathrm{Sr}_{x} \mathrm{Cu}_{1-y^{-}}$ $\mathrm{Ru}_{y} \mathrm{O}_{4-\delta}$ exists in the regions $0 \leqslant x \leqslant 2$ and $0 \leqslant y \leqslant 1$ with $x \geqslant 2 y$ and $x<1+2 y$, which are illustrated in the schematic phase diagram of Fig. 1. Two of the most important parameters that control the electronic behavior of these materials are the valences of the $\mathrm{Cu}$ and $\mathrm{Ru}$ ions. For $\delta=0$ and $x=2 y, \mathrm{Cu}$ and $\mathrm{Ru}$ have the valence states of $\mathrm{Cu}(\mathrm{II})$ and of $\mathrm{Ru}(\mathrm{IV})$, as in $\mathrm{La}_{2} \mathrm{CuO}_{4}$ and $\mathrm{Sr}_{2} \mathrm{RuO}_{4}$, respectively. For $x>2 y$, thermogravimetric measurements have shown that up to $40 \%$ of the $\mathrm{Ru}$ or Cu cations adopt a higher oxidation state [7,8], which then is either due to formation of $\mathrm{Cu}(\mathrm{III})$ or $\mathrm{Ru}(\mathrm{V})$ ions. In the case of high values of the ratio $x / 2 y$, the system tends to become oxygen-deficient. This leads finally to a breakdown of the $\mathrm{K}_{2} \mathrm{NiF}_{4}$-type structure when the oxygen deficiency reaches $\delta \leqslant 0.3$ [7]. Within a simple ionic picture copper is in $\mathrm{a} \mathrm{Cu}^{2+}\left(3 \mathrm{~d}^{9}\right)$ state in $\mathrm{La}_{2} \mathrm{CuO}_{4}$. Strong tetragonal elongation of the $\mathrm{CuO}_{6}$ octahedron lifts the degenracy of the $\mathrm{e}_{\mathrm{g}}$ orbitals -

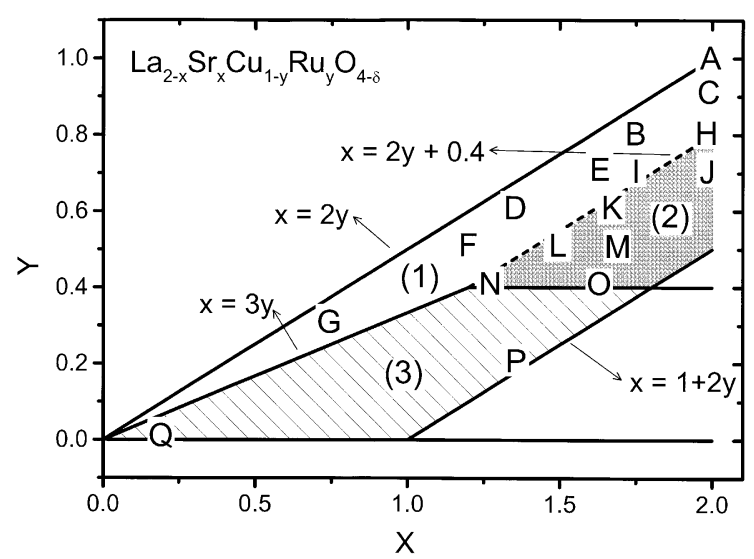

Fig. 1. Schematic phase diagram of $\mathrm{La}_{2-x} \mathrm{Sr}_{x} \mathrm{Cu}_{1-y} \mathrm{Ru}_{y} \mathrm{O}_{4}$, which is divided into three regions for $x>2 y$. The lines $x=2 y$, $x=3 y$ and $x=2 y+0.4$ make region (1) [light grey shading], where we have the Ru valence $v(\mathrm{Ru})<5$ and $\delta=0$. The lines $x=2 y+0.4$ and $y=0.4$ make region (2) [dark grey shading], where we have $v(\mathrm{Ru}) \leqslant 5$ and $\delta \geqslant 0$. The region (3) [hatched] lies below lines $x=3 y$ and $y=0.4$, where we have $v(\mathrm{Ru})=5$ and $\delta>0$. The capital letters on the diagram indicate the stoichiometry of each sample, as listed in Table 1. For details, see text. $\mathrm{d}\left(x^{2}-y^{2}\right)$ and $\mathrm{d}\left(z^{2}\right)$ - with the former being formally half-filled. According to the Zaanen-Sawatzky-Allen classification scheme, $\mathrm{La}_{2} \mathrm{CuO}_{4}$ is a charge transfer insulator, in which the on-site Coulomb correlation energy $U_{\mathrm{dd}},(>8 \mathrm{eV})$ is greater than the charge transfer energy, $\Delta[9]$. This results in a gap defined by the charge transfer energy between the $\mathrm{O} 2 \mathrm{p}$ and $\mathrm{Cu} 3 \mathrm{~d}$ dominated states. Thus, the holes near the Fermi energy $\left(E_{\mathrm{F}}\right)$ induced by $\mathrm{Sr}$ doping have mainly $\mathrm{O} 2 \mathrm{p}$ character. In the case of the undoped $4 \mathrm{~d}$ transition metal oxide $\mathrm{Sr}_{2} \mathrm{RuO}_{4}$, the $\mathrm{Ru} 4 \mathrm{~d}^{4}$ configuration gives rise to metallic behavior, since significant the dispersion of 4d-related states and the strong hybridization between $\mathrm{Ru} 4 \mathrm{~d}$ and $\mathrm{O}$ $2 p$ states smear out a possible splitting of the $t_{2 g}$ orbitals induced by the Jahn-Teller effect. The in plane resistivity has a linear temperature dependence from 20 to $300 \mathrm{~K}$. Energy band structure calculations indicate that three hybridized $\mathrm{Ru} d-\mathrm{O}$ $2 \mathrm{p} \pi$ bands cross $E_{\mathrm{F}}[10,11]$, where the density of states has mainly $\mathrm{Ru} 4 \mathrm{~d}$ character mixed with some O $2 p$ character.

In the mixed $\mathrm{Cu} / \mathrm{Ru}$ system, the question then arises as to whether for $x>2 y$ charge balance is achieved by hole creation in $\mathrm{Cu} 3 \mathrm{~d}$ states, giving rise to $\mathrm{Cu}(\mathrm{III})$ ions, or in $\mathrm{Ru} 4 \mathrm{~d}$ states resulting in $\mathrm{Ru}(\mathrm{V})$. In each case the electronic and magnetic properties are immediately an interesting issue.

Spectroscopic studies using X-ray absorption (XAS) at the $\mathrm{Cu} \mathrm{L} \mathrm{L}_{3,2}$ and $\mathrm{O} \mathrm{K}$ edges are well known to be standard methods for studying $\mathrm{Cu}$ valence and the hybridization between $\mathrm{Cu} 3 \mathrm{~d}$ and O $2 p$ states in cuprates [12-17]. In addition, our previous combined theoretical and experimental work on model $\mathrm{Ru}(\mathrm{IV})$ and $\mathrm{Ru}(\mathrm{V})$ oxides indicated that the $\mathrm{Ru} \mathrm{L}_{2,3}$ XAS spectra - as concerns both their energy position and spectral profile are sensitive to the valence state of $\mathrm{Ru}$ [18]. In this contribution we present a systematic study of the $\mathrm{La}_{2-x} \mathrm{Sr}_{x} \mathrm{Cu}_{1-y} \mathrm{Ru}_{y} \mathrm{O}_{4-\delta}$ system using XAS at the $\mathrm{Cu} 2 \mathrm{p}_{1 / 2,3 / 2}\left(\mathrm{~L}_{2,3}\right)$, Ru $2 \mathrm{p}_{1 / 2,3 / 2}\left(\mathrm{~L}_{2,3}\right)$, and $\mathrm{O} 1 \mathrm{~s}(\mathrm{~K})$ thresholds with the aim of answering the above questions. In addition, we have employed magnetization studies to explore whether the system exhibits superconductivity or long-range magnetic order and have carried out electrical resistivity measurements to monitor the effects of the $4 d-3 d$ interaction. 


\section{Experimental}

Polycrystalline samples of $\mathrm{La}_{2-x} \mathrm{Sr}_{x} \mathrm{Cu}_{1-y} \mathrm{Ru}_{y^{-}}$ $\mathrm{O}_{4-\delta}$ were prepared according to the procedures given in [7]. Throughout this contribution, we will refer to the systems in question using capital letters which represent a set of values for $x, y$ and $\delta$ denoted $(x, y, \delta)$ which are summarized in Table 1. $\mathrm{The} \mathrm{Sr}_{4} \mathrm{Ru}_{2} \mathrm{O}_{9}$ sample was prepared as described in [19]. The purity of the compounds was checked using X-ray powder diffraction (XRD). All samples (unless otherwise stated) were found to be single phase. The $\mathrm{K}_{2} \mathrm{NiF}_{4}$-type structure was verified using Rietveld refinements as shown in Fig. 2. Detailed information regarding these refinements can be found in $[7,8]$.

The magnetic investigations reported here were performed using a SQUID (VTS-905 from Biomagnetic Materials) and were carried out in the temperature range 6-300 $\mathrm{K}$ with an external magnetic field of $0.1 \mathrm{~T}$. Electrical resistivity measurements were performed on pressed powder pellets in the temperature range $300-575 \mathrm{~K}$ using a standard four-probe technique and a HewlettPackard 4284A supply.

Table 1

$\mathrm{Ru}$ valence $v(\mathrm{Ru})$ in $\mathrm{La}_{2-x} \mathrm{Sr}_{x} \mathrm{Cu}_{1-y} \mathrm{Ru}_{y} \mathrm{O}_{4-\delta}$ as obtained from Eqs. (3)-(5) (see text)

\begin{tabular}{llllll}
\hline $\begin{array}{l}\text { Sample } \\
\text { name }\end{array}$ & $X$ & $Y$ & $v(\mathrm{Ru})$ & $\delta$ & Magnetism \\
\hline $\mathrm{A}$ & 2 & 1 & 4 & 0 & $\mathrm{SG}$ \\
$\mathrm{B}$ & 1.76 & 0.8 & 4.20 & 0 & $\mathrm{SG}$ \\
$\mathrm{C}$ & 2 & 0.9 & 4.22 & 0 & $\mathrm{SG}$ \\
$\mathrm{D}$ & 1.36 & 0.6 & 4.27 & 0 & $\mathrm{SG}$ \\
$\mathrm{E}$ & 1.64 & 0.7 & 4.34 & 0 & $\mathrm{SG}$ \\
$\mathrm{F}$ & 1.2 & 0.5 & 4.40 & 0 & $\mathrm{SG}$ \\
$\mathrm{G}$ & 0.74 & 0.3 & 4.47 & 0 & $\mathrm{AF}$ \\
$\mathrm{H}$ & 2 & 0.8 & 4.50 & 0 & $\mathrm{SG}$ \\
$\mathrm{I}$ & 1.76 & 0.7 & 4.51 & 0 & $\mathrm{SG}$ \\
$\mathrm{J}$ & 2 & 0.7 & 4.57 & 0.1 & $\mathrm{SG}$ \\
$\mathrm{K}$ & 1.68 & 0.6 & 4.67 & 0.04 & $\mathrm{SG}$ \\
$\mathrm{L}$ & 1.5 & 0.5 & 4.80 & 0.05 & $\mathrm{SG}$ \\
$\mathrm{M}$ & 1.7 & 0.5 & 4.80 & 0.15 & $\mathrm{SG}$ \\
$\mathrm{N}$ & 1.28 & 0.4 & 5 & 0.04 & $\mathrm{CW}$ \\
$\mathrm{O}$ & 1.64 & 0.4 & 5 & 0.22 & $\mathrm{CW}$ \\
$\mathrm{P}$ & 1.36 & 0.2 & $>5$ & 0.28 & $\mathrm{CW}$ \\
\hline
\end{tabular}

$\delta$ was obtained from thermogravimetric measurements. SG, $\mathrm{AF}$ and $\mathrm{CW}$ denote spin-glass, antiferromagnetic and CurieWeiss magnetic behaviour, respectively.
The combined thermogravimetric/mass spectrometric measurements were carried out using a Netzsch STA 409 thermoanalytic system connected to a Balzers QMG 421 mass spectrometer by a capillary coupling system. In these experiments about $50 \mathrm{mg}$ of material was heated to 1000 ${ }^{\circ} \mathrm{C}$ at a rate of $10^{\circ} \mathrm{C} / \mathrm{min}$ under a constant flow of $50 \mathrm{ml} / \mathrm{min}$ forming gas $\left(\mathrm{N}_{2} / \mathrm{H}_{2} 95: 5 \%\right)$.

The $\mathrm{O} K$ and $\mathrm{Cu} \mathrm{L} \mathrm{L}_{2,3}$ XAS spectra were recorded at BESSY (Berlin) using the SX700/II monochromator. The $\mathrm{O} \mathrm{K}$ and $\mathrm{Cu} \mathrm{L}_{2,3}$ XAS spectra were recorded in fluorescence yield (FY) and total electron yield (TEY) modes, respectively. At the $\mathrm{O} K$ and $\mathrm{Cu} \mathrm{L}_{3}$ thresholds, the experimental resolutions were 0.2 and $0.5 \mathrm{eV}$, respectively. Prior to the measurements, the sample surfaces were scraped in situ with a diamond file at a base pressure of $5 \times 10^{-10} \mathrm{mbar}$. The $\mathrm{O} \mathrm{K}$ and $\mathrm{Cu} \mathrm{L} \mathrm{L}_{2,3}$ XAS spectra were normalized to the beam current. In addition, the $\mathrm{O} \mathrm{K}$ data have been corrected for the energy-dependent incident X-ray flux and for self-absorption effects according to a procedure described elsewhere [20,21].

For systems built up of corner sharing of $\mathrm{CuO}_{4}$ plaquettes $\left(180^{\circ} \mathrm{Cu}-\mathrm{O}-\mathrm{Cu}\right.$ interaction pathway), the spectral features from a $\mathrm{Cu}$ (III) state should lie $\sim 10 \mathrm{eV}$ above the main peak as a weak, broad satellite $[15,22,23]$. In contrast to the preliminary work of some of us [24] - in which only the main peak in $\mathrm{Cu} \mathrm{L}_{3}$ XAS spectra were presented and the satellite structures for the $2 p 3 d^{9}$ final state were not shown - now we measured both the $\mathrm{Cu} \mathrm{L}_{3}$ and $\mathrm{Cu} \mathrm{L}_{2}$ spectra, thus not missing out on any important information. $\mathrm{CuO}$ was used for energetic calibration at the $\mathrm{Cu} \mathrm{L}_{2,3}$ and $\mathrm{O} \mathrm{K}$ thresholds after each injection into the storage ring. A long acquisition time was used for samples with low $\mathrm{Cu}$ concentration, for example $\mathrm{B}(1.76 ; 0.8,0)$ and $\mathrm{C}(2,0.9,0)$ to improve the signal-background ratio [25].

The $\mathrm{Ru} \mathrm{L}_{2,3}$ XAS spectra were recorded in transmission geometry at the EXAFS-II beamline at HASYLAB, using a $\operatorname{Si}(111)$ double-crystal monochromator. This resulted in an experimental resolution of $\cong 0.8 \mathrm{eV}$ (FWHM) at the $\mathrm{Ru} \mathrm{L}_{3}$ threshold $(2838 \mathrm{eV})$. Depending on the $\mathrm{Ru}$ content, $5-10 \mathrm{mg}$ of the material in question was 


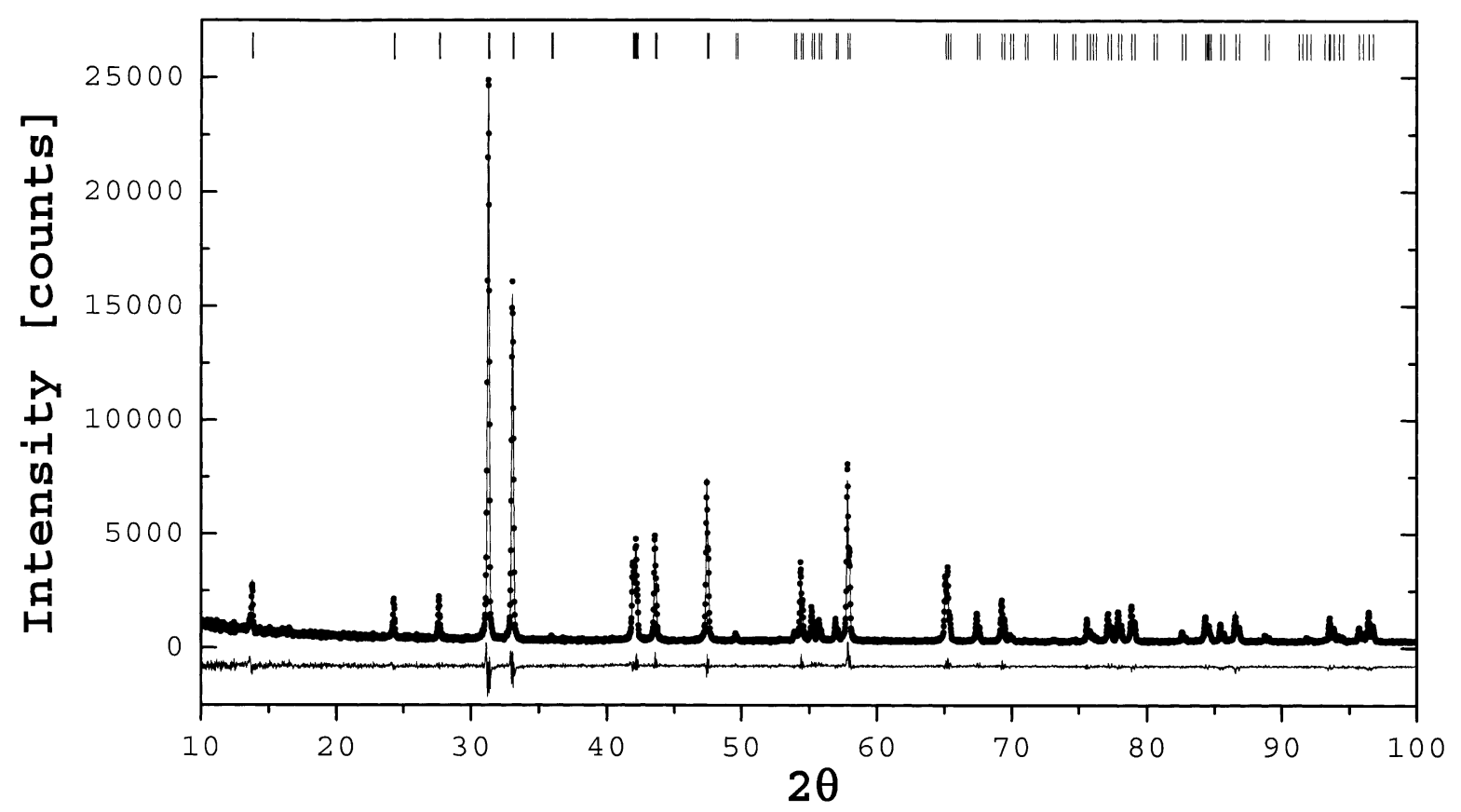

Fig. 2. Rietveld refinement data for the $\mathrm{La}_{0.36} \mathrm{Sr}_{1.64} \mathrm{Cu}_{0.3} \mathrm{Ru}_{0.7} \mathrm{O}_{4-\delta}$ sample.

mixed with $20 \mathrm{mg}$ polyethylene powder and pressed into a pellet of $13 \mathrm{~mm}$ diameter.

\section{Results}

\subsection{Magnetism and conductivity}

A large variation of the magnetic properties was found in the system $\mathrm{La}_{2-x} \mathrm{Sr}_{x} \mathrm{Cu}_{1-y} \mathrm{Ru}_{y} \mathrm{O}_{4-\delta}$. In this paper, only three typical examples are shown. A more extended study will be published elsewhere. As can be seen from Fig. 3, the sample $\mathrm{P}(1.36,0.2,0.28)$ (dashed curve) shows an almost ideal Curie-Weiss (CW) behavior in the magnetic susceptibility between $6 \mathrm{~K}$ and room temperature, which represents the magnetic behavior found for most of the samples studied. In a number of samples, e.g. $E(1.64,0.7,0)$ in Fig. 3, the magnetic susceptibility, $\chi_{\mathrm{mol}}$, shows a markedly different behavior below $20 \mathrm{~K}$, depending on whether the sample is field-cooled or zero-field-cooled. The data indicate a typical spin-glass (SG) behavior which had been observed previously by Kim et al. for the series $\mathrm{LaSr}_{n} \mathrm{CuRuO}_{n+5}$ (with $n=1,2,3$ ) [6].
The third class of magnetic behavior is shown for the sample $G(0.74,0.3,0)$ in Fig. 3, which shows an antiferromagnetic phase (AF) transition at

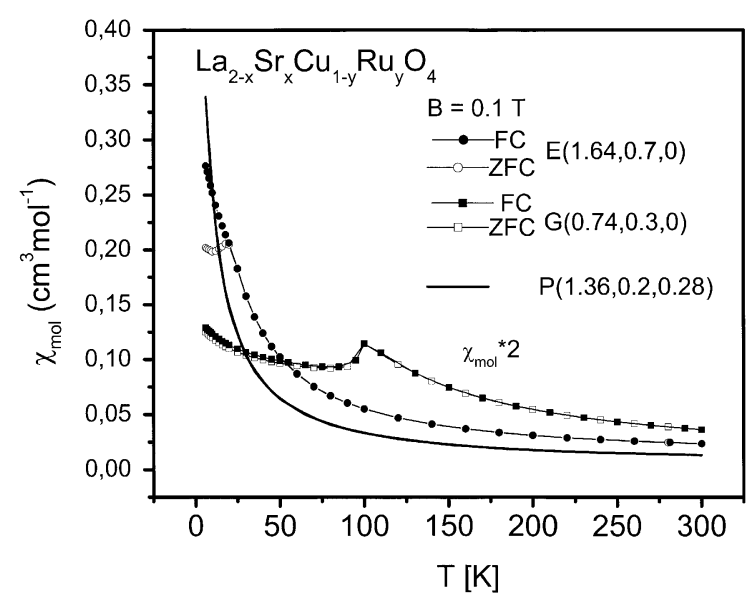

Fig. 3. Magnetic susceptibility, $\chi_{\text {mol }}$, of $\mathrm{La}_{2-x} \mathrm{Sr}_{x} \mathrm{Cu}_{1-y} \mathrm{Ru}_{y} \mathrm{O}_{4-\delta}$, showing a Curie-Weiss behavior for $\mathrm{P}(1.36,0.2,0.28)$ (solid line), a spin-glass behavior for $\mathrm{E}(1.64,0.7,0)$ (filled circles for field-cooled and open circles for zero-field-cooled), and an antiferromagnetic transition at $T_{\mathrm{N}} \approx 117 \mathrm{~K}$ for $\mathrm{G}(0.74,0.3,0)$ (filled squares for field-cooled and open squares for zero-fieldcooled). 
$T_{\mathrm{N}} \approx 117 \mathrm{~K}$. Below $T_{\mathrm{N}}$ the field-cooled and the zero-field-cooled curves are only slightly split. This class of compounds was found to possess an unusually large a axis and a short $\mathrm{c}$ axis [7]. The magnetic properties of studied compounds are summarized in Table 1. The electrical resistivity, $\rho$, exhibits a maximum at $y \approx 0.5$ for a given $x$, in agreement with previous work [6], where an increase of $\rho$ with y in the region $y<0.5$ had been reported. This could be a consequence of the disorder induced by the randomly distributed $\mathrm{Cu}$ and $\mathrm{Ru}$ atoms in the $(\mathrm{Cu}, \mathrm{Ru}) \mathrm{O}_{2}$ planes. Along a similar vein, it has been found that metallic $\mathrm{Sr}_{2} \mathrm{RuO}_{4}$ can be driven insulating through changes in doping in $\mathrm{Sr}_{2} \mathrm{Ir}_{1-x} \mathrm{Sr}_{x} \mathrm{O}_{4} \quad$ [26]. Previously, $\mathrm{La}_{0.5} \mathrm{Sr}_{1.5} \mathrm{Cu}_{0.5} \mathrm{Ru}_{0.5} \mathrm{O}_{4}$ and $\mathrm{La}_{0.25} \mathrm{Sr}_{1.75} \mathrm{Cu}_{0.5} \mathrm{Ru}_{0.5} \mathrm{O}_{4}$ have been prepared with the aim of obtaining metallic formal $\mathrm{Ru}(\mathrm{V})$ oxides [5]. However, these systems were found to be semiconducting and there was no evidence for the existence of longrange magnetic order.

\subsubsection{Thermogravimetry}

The reduction of the different samples started between 300 and $450{ }^{\circ} \mathrm{C}$ and was finished between $650{ }^{\circ} \mathrm{C}$ and $900{ }^{\circ} \mathrm{C}$. As the reaction temperature strongly depends on both the chemical composition and the morphology of the samples (in particular the particle size), we were unable to find a systematic relationship between the start or end temperatures and the values of $x, y$ and $\delta$, respectively. The mass spectra (monitored simultaneously) indicated that $\mathrm{H}_{2} \mathrm{O}$ was the only volatile reaction product. This is an important additional information as weight losses due to the evolution of other gases (e.g., $\mathrm{CO}_{2}$ from unreacted carbonates) would have led to incorrect values of $\delta$. In addition, the absence of such signals can be taken as an additional confirmation of the sample quality.

From the weight loss during reduction and the known values of $x$ and $y$, the oxygen deficiency $\delta$ can easily be calculated. Fig. 4 shows a plot of $\delta$ as a function of $x$ for various samples with $y=0.1$, $0.3, \quad 0.5$ and 0.7 , respectively. From repeated measurements of selected samples we estimate the error in $\delta$ to be approximately \pm 0.03 . From Fig. 4 it can be seen that for small ratios of $x / y$ the ox-

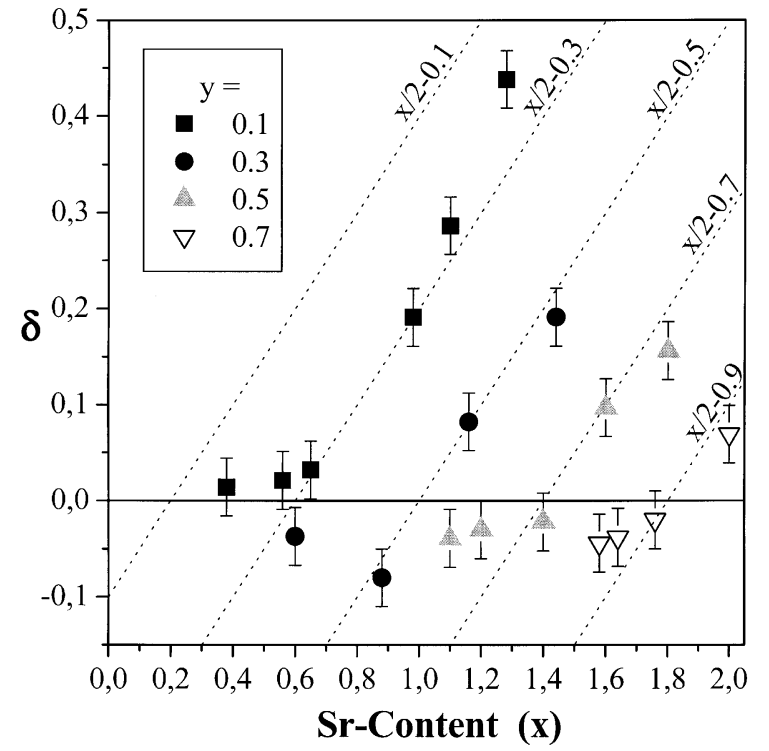

Fig. 4. Dependence of the measured oxygen deficiency $\delta$ on $x$ and $y$. Dotted lines indicate the expected values for. $\delta=x / 2-y-0.2$. Error bars represent the estimated error of \pm 0.03 .

ygen content is close to the value of 4 . On increasing this ratio, the structure starts to become oxygen deficient. The dependence of $\delta$ on $x$ and $y$ can well be approximated by the following formulae:

$\delta \approx 0$ for $x \leqslant 2 y+0.4$

$\delta \approx x / 2-y-0.2$ for $x>2 y+0.4$.

For values of $\delta>0.3$ the $\mathrm{K}_{2} \mathrm{NiF}_{4}$ structure becomes unstable and impurity peaks can be found in the XRD patterns. For example, a sample with $x=1.28, y=0.1$, already contained minor impurity phases visible in the XRD traces. Therefore, it is not surprising that this sample shows a deviation from the above relationship as can be seen in Fig. 4.

\section{2. $C u L_{2,3} X A S$ spectra}

Fig. 5 shows the $\mathrm{Cu} \mathrm{L}_{2,3}$ XAS spectra of some selected compounds of the series $\mathrm{La}_{2-x} \mathrm{Sr}_{x} \mathrm{Cu}_{1-y}$ $\mathrm{Ru}_{y} \mathrm{O}_{4-\delta}$, together with those of $\mathrm{CuO}$ and $\mathrm{La}_{2} \mathrm{Li}_{0.5} \mathrm{Cu}_{0.5} \mathrm{O}_{4}$ as $\mathrm{Cu}$ (II) and $\mathrm{Cu}(\mathrm{III})$ references, respectively. The strong single peak observed for all $\mathrm{La}_{2-x} \mathrm{Sr}_{x} \mathrm{Cu}_{1-y} \mathrm{Ru}_{y} \mathrm{O}_{4-\delta}$ systems lies at energies 


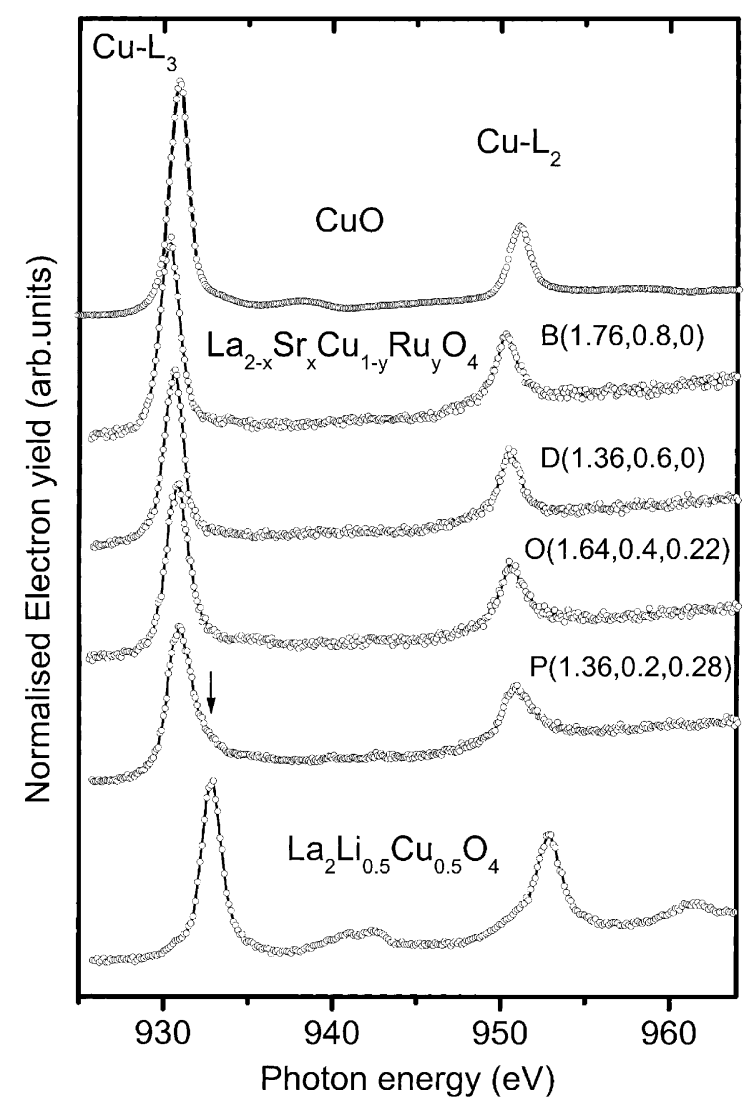

Fig. 5. $\mathrm{Cu} \mathrm{L}_{2,3}$ XAS spectra of selected $\mathrm{La}_{2-x} \mathrm{Sr}_{x} \mathrm{Cu}_{1-y} \mathrm{Ru}_{y} \mathrm{O}_{4-\delta}$ compounds together with spectra of $\mathrm{CuO}$ and $\mathrm{La}_{2} \mathrm{Li}_{0.5} \mathrm{Cu}_{0.5} \mathrm{O}_{4}$ as $\mathrm{Cu}(\mathrm{II})$ and $\mathrm{Cu}(\mathrm{III})$ references, respectively.

ranging from 930.7 to $931.4 \mathrm{eV}$, and is shifted by only $|\Delta E| \leqslant 0.3 \mathrm{eV}$ with respect to that of $\mathrm{CuO}$ at $931.2 \mathrm{eV}$ for most of the samples. Sample $\mathrm{B}(1.76,0.8,0)$ is one exception with a $0.5 \mathrm{eV}$ shift to lower energy. We attribute this larger shift to strong excitonic effects [12], which is a reasonable supposition considering the narrow linewidth for this oxide. The single peak in $\mathrm{CuO}$ is assigned to a $2 \mathrm{p} 3 \mathrm{~d}^{10}$ final state arising from the $3 \mathrm{~d}^{9}$ initial state of $\mathrm{Cu}(\mathrm{II})$. In contrast, the strong peak in the $\mathrm{Cu}(\mathrm{III})$ reference compound $\mathrm{La}_{2} \mathrm{Li}_{0.5} \mathrm{Cu}_{0.5} \mathrm{O}_{4}$ lies $1.7 \mathrm{eV}$ above the peak of $\mathrm{CuO}$ and is attributed to a predominantly 2 p $3 d^{10} \mathrm{~L}$ final state ( $\mathrm{L}$ denotes a hole in the $\mathrm{O} 2 \mathrm{p}$ ligand orbitals). The weak satellite at $\sim 9 \mathrm{eV}$ above the main peak in $\mathrm{La}_{2} \mathrm{Li}_{0.5} \mathrm{Cu}_{0.5} \mathrm{O}_{4}$ is assigned to a predominantly $2 \mathrm{p} 3 \mathrm{~d}^{9}$ final state, which thus exhibits multiplet splitting $[13,17,22]$.
The $\mathrm{Cu} \mathrm{L} \mathrm{L}_{2,3}$ edges therefore clearly reveal that in most compounds discussed here the copper ions remain divalent $[\mathrm{Cu}(\mathrm{II})]$. Only at very high $x / 2 y$ ratios in region 3 of Fig. 1 (i.e., close to the breakdown of the $\mathrm{K}_{2} \mathrm{NiF}_{4}$-type structure) such as for $\mathrm{P}(1.36,0.2,0.28)$, can one see a weak shoulder (indicated by an arrow in Fig. 5) at the energy of the main peak of $\mathrm{La}_{2} \mathrm{Li}_{0.5} \mathrm{Cu}_{0.5} \mathrm{O}_{4}$. Such a weak shoulder has also observed previously in $\mathrm{La}_{2-x} \mathrm{Sr}_{x} \mathrm{CuO}_{4}$ [12,14,27], where the holes in $\mathrm{CuO}_{2}$ plane created by $\mathrm{Sr}$ doping have mainly $\mathrm{O} 2 \mathrm{p}$ and only little $\mathrm{Cu} 3 \mathrm{~d}$ character. This is a result of the fact that to achieve a $3 \mathrm{~d}^{8}$ configuration for $\mathrm{Cu}^{3+}$ state in a simple ionic description, it would be necessary to overcome the particularly large Coulomb correlation energy $U_{\mathrm{dd}}$. In the case of $\mathrm{La}_{2} \mathrm{Li}_{0.5} \mathrm{Cu}_{0.5} \mathrm{O}_{4}$, each $\mathrm{CuO}_{4}$ plaquette (which is isolated from the next $\mathrm{CuO}_{4}$ plaquette by the $\mathrm{Li}-\mathrm{O}$ sublattice) has one additional hole. This hole has mainly $\mathrm{O} 2 \mathrm{p}$ character resulting in a dominant 2 p $3 \mathrm{~d}^{10} \mathrm{~L}$ final state in $\mathrm{Cu} \mathrm{L}_{2,3}$ XAS. A similar spectral feature has also been found in the $\mathrm{Cu}$ (III) oxide $\mathrm{NaCuO}_{2}$ in which a $90^{\circ} \mathrm{Cu}-\mathrm{O}-\mathrm{Cu}$ interaction pathway causes the inter-plaquette interaction to be weak, leading to a behavior of analogous that an isolated $\mathrm{CuO}_{4}$ plaquette [23]. In strong contrast to these quasi isolated $\mathrm{Cu}(\mathrm{III}) \mathrm{O}_{4}$ plaquette systems, for the $\mathrm{Cu}$ (III) oxide $\mathrm{LaCuO}_{3}$ which has an $180^{\circ} \mathrm{Cu}-\mathrm{O}-\mathrm{Cu}$ interaction pathway leading to stronger inter-plaquette hopping and metallic conductivity, a double-peaked $\mathrm{Cu}_{3}$ structure has been found [22].

\section{3. $R u L_{2,3} X A S$ spectra}

The fact that the $\mathrm{Cu}$ valence remains essentially unchanged upon $\mathrm{Sr}$ doping leads to the conclusion that the $\mathrm{Ru}$ ions play the central role as regards the charge balance in these compounds. In the following, we first present our observations as regards the spectral response at the $\mathrm{Ru} \mathrm{L}_{2,3}$ excitation edge for a change of $\mathrm{Ru}$ valence and then give a theoretical interpretation of the data. For $4 \mathrm{~d}$ transition metal (TM) oxides, the larger band-like character of the $4 \mathrm{~d}$ states and the weaker Coulomb repulsion energy $U_{\mathrm{dd}}$ mean that these systems are generally significantly less dominated by correlation effects than their $3 \mathrm{~d}$ counterparts. 
Thus, it costs less energy to remove a $4 \mathrm{~d}$ electron from a $\mathrm{Ru}$ ion than to remove a $3 \mathrm{~d}$ electron from a $\mathrm{Cu}$ ion. Compared with the situation as regards $3 \mathrm{~d}$ TM $\mathrm{L}_{2}$ and $\mathrm{L}_{3}$ XAS spectra [28], both the experimental and theoretical study of $4 \mathrm{~d} T M \mathrm{~L}_{2,3}$ XAS spectra lag far behind. It is usually assumed that the $4 \mathrm{~d}$ TM L L 2,3 XAS spectra reflect directly the unoccupied $4 \mathrm{~d}$ orbitals, and thus the spectra have often been interpreted in terms of crystal-field or molecular-orbital theories [29-32]. In the case of $\mathrm{O}_{\mathrm{h}}$ local symmetry, it is then expected that the intensity ratio of transitions into the crystal-fieldsplit $\mathrm{t}_{2 \mathrm{~g}}$ and $\mathrm{e}_{\mathrm{g}}$ states $I\left(\mathrm{t}_{2 \mathrm{~g}}\right) / I\left(\mathrm{e}_{\mathrm{g}}\right)$ is 0.5 for $\mathrm{Ru}(\mathrm{IV})$ $\left[4 \mathrm{~d}^{4}\right]$ and increases to 0.75 for $\mathrm{Ru}(\mathrm{V})\left[4 \mathrm{~d}^{3}\right]$ at both the $\mathrm{L}_{2}$ and the $\mathrm{L}_{3}$ edges. Recently, however, it was recognized that the intra-atomic Coulomb interaction and the $4 \mathrm{~d}$ spin-orbit coupling strongly modify the spectral features in $\mathrm{Ru} \mathrm{L}_{2,3}$ XAS spectra $[18,33]$, as concerns both their energy position and the intensity ratio of the $t_{2 g}$ and $e_{g}$-related features. Therefore only a combined experimental and theoretical study in which the model explicitly takes multiplet and spin-orbit coupling effects into account can give reliable information on the valence of $\mathrm{Ru}$.

For simplicity, we first show in Fig. 6 the $\mathrm{Ru}$ $\mathrm{L}_{2,3}$ XAS spectra of $\mathrm{Sr}_{2} \mathrm{Cu}_{1-y} \mathrm{Ru}_{y} \mathrm{O}_{4}$ with $y=$ $1[\mathrm{~A}(2,1,0)], 0.9[\mathrm{C}(2,0.9,0)]$, and $0.7[\mathrm{~J}(2,0.7,01)]$ together with those of $\mathrm{Sr}_{4} \mathrm{Ru}_{2} \mathrm{O}_{9}$ (bottom) as a $\mathrm{Ru}(\mathrm{V})$ reference. To ease comparison, the $\mathrm{L}_{2}$ spectra (open symbols) have been shifted by 129 $\mathrm{eV}$ (the Ru 2p spin-orbit splitting) and have been multiplied by 2.1 such that their high energy feature matches the corresponding feature in the $\mathrm{L}_{3}$ spectra (filled symbols). In each case, the lower and the higher energy component basically reflects transitions into $t_{2 \mathrm{~g}}$ and $\mathrm{e}_{\mathrm{g}}$-related states, respectively. The intensity ratio, $I\left(\mathrm{t}_{2 \mathrm{~g}}\right) / I\left(\mathrm{e}_{\mathrm{g}}\right)$, is higher at the $L_{3}$ edge than at the $L_{2}$ edge for the $R u(I V)$ compound $\mathrm{Sr}_{2} \mathrm{RuO}_{4}$, but this situation is reversed for the $\mathrm{Ru}(\mathrm{V})$ compound $\mathrm{Sr}_{4} \mathrm{Ru}_{2} \mathrm{O}_{9}$. The observed spectral ratios are significantly different from those expected from crystal-field and molecular-orbital theories, as has been discussed in detail in [18]. In addition, on going from $\mathrm{Ru}(\mathrm{IV})$ to $\mathrm{Ru}(\mathrm{V})$, the energy position of both components of the $\mathrm{L}_{2}$ and $\mathrm{L}_{3}$ XAS spectra are shifted by $1.5 \mathrm{eV}$ to higher energies.
The changes in the $\mathrm{Ru} \mathrm{L}_{2,3}$ XAS spectra occurring upon increasing $\mathrm{Ru}$ valence described above can be well reproduced by crystal-fieldmultiplet calculations (CFMCs) as is shown in Fig. 6 . The solid and dashed lines below the spectra of $\mathrm{Sr}_{2} \mathrm{RuO}_{4}$ and $\mathrm{Sr}_{4} \mathrm{Ru}_{2} \mathrm{O}_{9}$ are the theoretical curves obtained for the $\mathrm{L}_{3}$ and $\mathrm{L}_{2}$ edges, respectively. The intensity ratio $I\left(\mathrm{t}_{2 \mathrm{~g}}\right) / I\left(\mathrm{e}_{\mathrm{g}}\right)$ at both the $\mathrm{L}_{2}$ and $\mathrm{L}_{3}$ edges has been found to be very sensitive to the intra-atomic Coulomb interactions, represented by the corresponding Slater integral and to the $4 \mathrm{~d}$ spin-orbit coupling [18,33]. Considering the strong covalency between the transition metal $\mathrm{d}$ and the

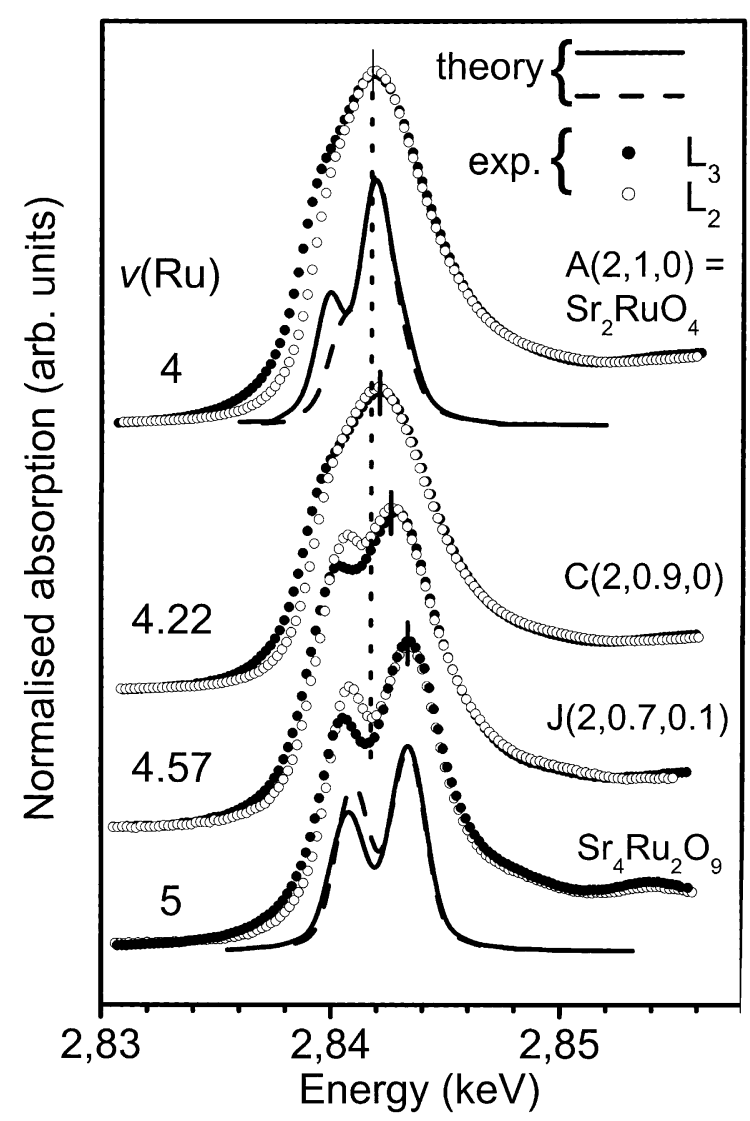

Fig. 6. The XAS spectra of $\mathrm{Sr}_{2} \mathrm{Cu}_{1-y} \mathrm{Ru}_{y} \mathrm{O}_{4}$ and of $\mathrm{Sr}_{4} \mathrm{Ru}_{2} \mathrm{O}_{9}$ as a $\mathrm{Ru}(\mathrm{V})$ reference at the $\mathrm{Ru} \mathrm{L}_{2}$ edge (open circles) and at the $\mathrm{Ru}$ $\mathrm{L}_{3}$ edge (filled circles). The $\mathrm{Ru} \mathrm{L}_{2}$ data have been shifted and multiplied to overlap with the $\mathrm{Ru} \mathrm{L}_{3}$ data. The theoretical $\mathrm{Ru}$ $\mathrm{L}_{2,3}$ XAS spectra from crystal-field-multiplet calculations for $\mathrm{Ru}(\mathrm{IV})$ and $\mathrm{Ru}(\mathrm{V})$ are shown as solid and dashed lines stand for the $\mathrm{L}_{3}$ and the $\mathrm{L}_{2}$ edges, respectively. $v(\mathrm{Ru})$ indicates the $\mathrm{Ru}$ valence. For details, see text. 
O $2 p$ states in these systems, the Slater integrals have to be reduced to $50 \%$ and $15 \%$ of their atomic values for $\mathrm{Ru}(\mathrm{IV})$ and $\mathrm{Ru}(\mathrm{V})$, respectively. The $4 \mathrm{~d}$ spin-orbit coupling is also very important. Neglecting it, the $t_{2 g}$-related peak for the $\mathrm{Ru}(\mathrm{IV}) 4 \mathrm{~d}^{4}$ configuration $\left(\mathrm{Sr}_{2} \mathrm{RuO}_{4}\right)$ should disappear [18], and the intensity ratio $I\left(\mathrm{t}_{2 \mathrm{~g}}\right) / I\left(\mathrm{e}_{\mathrm{g}}\right)$ should be stronger at $\mathrm{L}_{3}$ than at $\mathrm{L}_{2}$ for the $\mathrm{Ru}(\mathrm{V})$ system $\left(\mathrm{Sr}_{4} \mathrm{Ru}_{2} \mathrm{O}_{9}\right)$ which is plainly not the case. On the basis of the experimental and theoretical spectra for the simple, La-free $\mathrm{Ru}(\mathrm{IV})$ and $\mathrm{Ru}(\mathrm{V})$ systems, we can thus conclude that the upward shift in energy position and the significantly larger $I\left(\mathrm{t}_{2 \mathrm{~g}}\right) / I\left(\mathrm{e}_{\mathrm{g}}\right)$ ratio at the $\mathrm{L}_{2}$ compared to the $\mathrm{L}_{3}$ edge indicate an increase of the $\mathrm{Ru}$ valence with increasing $\mathrm{Cu}$ concentration in the $\mathrm{Sr}_{2} \mathrm{Cu}_{1-y} \mathrm{Ru}_{y} \mathrm{O}_{4}$ system.

We now move on to the more complicated $\mathrm{La}_{2-x} \mathrm{Sr}_{x} \mathrm{Cu}_{1-y} \mathrm{Ru}_{y} \mathrm{O}_{4-\delta}$ systems. Firstly, we have calculated the spectra of the $4 \mathrm{~d}^{4}$ and $4 \mathrm{~d}^{3}$ systems as a function of the crystal field $10 \mathrm{Dq}$ within a large region and found the intensity ratios to be relatively insensitive to the value of $10 \mathrm{Dq}$. Thus, as a first step, we estimated the crystal field parameter for the $\mathrm{Ru}(\mathrm{IV})$ and $\mathrm{Ru}(\mathrm{V})$ systems from the $\mathrm{O} \mathrm{K}$ XAS spectra. As regards the Ru L XAS spectra, the important parameter in the simulation of the experimental spectra is the degree of reduction of the Slater integrals, which reflects a significant bandwidth of the $4 \mathrm{~d}$ states and strong $\mathrm{Ru} 4 \mathrm{~d}$ and O $2 p$ covalence.

Bearing in mind Eqs. (1) and (2) introduced above to approximate the thermogravimetric data on the oxygen deficiency $\delta$ in $\mathrm{La}_{2-x} \mathrm{Sr}_{x} \mathrm{Cu}_{1-y} \mathrm{Ru}_{y}$ $\mathrm{O}_{4-\delta}$, and remembering that the $\mathrm{Cu}$ ions remains essentially divalent, the ratio $n(V)=N[\mathrm{Ru}(\mathrm{V})] /$ $\{N[\mathrm{Ru}(\mathrm{V})]+N[\mathrm{Ru}(\mathrm{IV})]\}$, where $N[\mathrm{Ru}(\mathrm{V})]$ and $N[\mathrm{Ru}(\mathrm{IV})]$ are number of $\mathrm{Ru}(\mathrm{V})$ and $\mathrm{Ru}(\mathrm{IV})$ ions, respectively, is obtained by

$n(V)=x / y-2$ for $\mathrm{x} \leqslant 2 y+0.4$,

$n(V)=0.4 / y \quad$ for $x>2 y+0.4$.

The $\mathrm{Ru}$ valence $v(\mathrm{Ru})$ is then given by

$v(\mathrm{Ru})=4+n(V)$.

The values of $v(\mathrm{Ru})$ obtained from to Eqs. (3)-(5) are summarized in Table 1. Now we can go back to the phase diagram shown in Fig. 1. The thermogravimetric data indicate that there are three regions for $x>2 y$. The lines $x=2 y, x=3 y$ and $x=2 y+0.4$ make region (1), in which we have the Ru valence $v(\mathrm{Ru})<5$ and $\delta=0$. In this region the holes are located only in the $\mathrm{RuO}_{6}$ units with both $\mathrm{Cu}\left(\mathrm{t}_{2 \mathrm{~g}}^{6} \mathrm{e}_{\mathrm{g}}^{3}\right)-\mathrm{Ru}\left(\mathrm{t}_{2 \mathrm{~g}}^{4} \mathrm{e}_{\mathrm{g}}^{0}\right)$ and $\mathrm{Cu}\left(\mathrm{t}_{2 \mathrm{~g}}^{6} \mathrm{e}_{\mathrm{g}}^{3}\right)-\mathrm{Ru}\left(\mathrm{t}_{2 \mathrm{~g}}^{3} \mathrm{e}_{\mathrm{g}}^{0}\right)$ interactions.

The lines $x=2 y+0.4$ and $y=0.4$ delineate region (2), where $v(\mathrm{Ru}) \leqslant 5$ and $\delta \geqslant 0$. In this region only the $\mathrm{Cu}\left(\mathrm{t}_{2 \mathrm{~g}}^{6} \mathrm{e}_{\mathrm{g}}^{3}\right)-\mathrm{Ru}\left(\mathrm{t}_{2 \mathrm{~g}}^{3} \mathrm{e}_{\mathrm{g}}^{0}\right)$ interaction is achieved in some compounds, such as $\mathrm{N}(1.28,0.4$, $0.04)$ and $\mathrm{O}(1.64,0.4,0.22)$. Anion vacancies are expected to have weaker effects on the low-lying $\mathrm{Ru}$ $\mathrm{t}_{2 \mathrm{~g}}$ manifolds than on the high-lying $\mathrm{Cu} \mathrm{e}_{\mathrm{g}}^{*}$ orbitals. The vacancies will lead to a redistribution of electron density from $z^{2}$ band to $x^{2}-y^{2}$ band [5]. The electronic structure of both compounds are very similar to that of $\mathrm{La}_{0.5} \mathrm{Sr}_{1.5} \mathrm{Cu}_{0.5} \mathrm{Ru}_{0.5} \mathrm{O}_{4}$ and $\mathrm{La}_{0.25} \mathrm{Sr}_{1.75} \mathrm{Cu}_{0.5} \mathrm{Ru}_{0.5} \mathrm{O}_{4-\delta}$ studied previously, in which attempts to observe metallic conductivity by doping-induced introduction of the $\mathrm{Ru}\left(\mathrm{t}_{2 \mathrm{~g}}^{3} \mathrm{e}_{\mathrm{g}}^{0}\right)$ configuration had failed [5]. Thus, considering this fact together with the above mentioned resistivity data, it would appear that itinerant electronic transport is hindered by the presence of $\mathrm{Cu}-\mathrm{O}-\mathrm{Ru}-\mathrm{O}-\mathrm{Cu}$ pathways.

Region (3) in Fig. 1 lies below the lines $x=3 y$ and $y=0.4$ and we have $v(\mathrm{Ru})=5$ and $\delta>0$. In this region the holes can be located in the $\mathrm{CuO}_{4}$ plaquattes as in the case of $\mathrm{La}_{2-x} \mathrm{Sr}_{x} \mathrm{CuO}_{4}$, however, the charge hopping is suppressed by the $\mathrm{Cu}-\mathrm{O}-\mathrm{Ru}-\mathrm{O}-\mathrm{Cu}$ interaction pathways as discussed above. The $\mathrm{Ru}$ valences of 4.22 for $\mathrm{C}(2,0.9,0)$ [region (1)] and 4.57 for $\mathrm{J}(2,0.7,0.1)$ [region (2)] are consistent with the conclusion presented here that the $\mathrm{Ru}$ valence increases with increasing $\mathrm{Cu}$ concentration in the $\mathrm{Sr}_{2} \mathrm{Cu}_{1-y}$ $\mathrm{Ru}_{y} \mathrm{O}_{4-\delta}$ system.

The $\mathrm{Ru} \mathrm{L}_{2,3}$ spectra of the more complicated $\mathrm{La}_{2-x} \mathrm{Sr}_{x} \mathrm{Cu}_{1-y} \mathrm{Ru}_{y} \mathrm{O}_{4-\delta}$ compounds $(x \neq 0$ and $y \neq 0)$ are shown in Fig. 7 with increasing ruthenium valence from top to bottom. One can clearly see a shift of the peak position to higher energy and an increase of the $I\left(\mathrm{t}_{2 \mathrm{~g}}\right) / I\left(\mathrm{e}_{\mathrm{g}}\right)$ intensity ratios at the $\mathrm{Ru} \mathrm{L}_{2}$ edge with increasing $\mathrm{Ru}$ valence. In the case of the sample $\mathrm{N}(1.28,0.4,0.04)$, the $\mathrm{Ru}$ is pentavalent i.e., $n(V)=1$, with the spectral fea- 


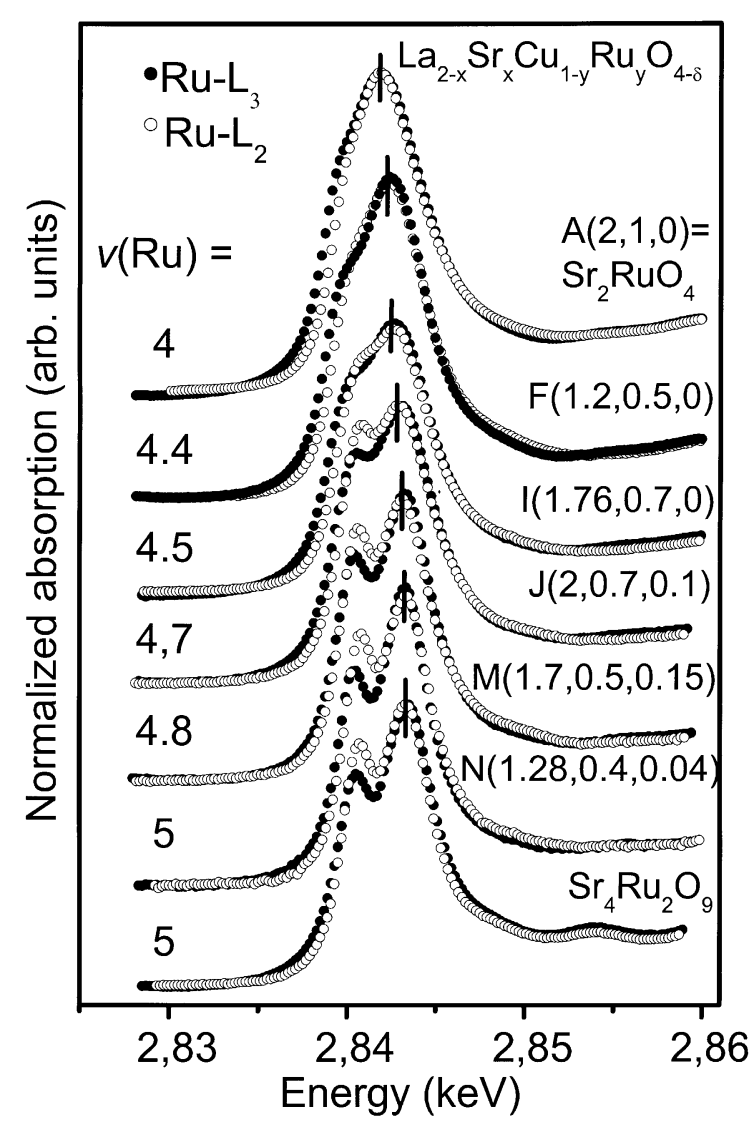

Fig. 7. $\mathrm{Ru} \mathrm{L} \mathrm{L}_{2,3}$ XAS spectra of selected $\mathrm{La}_{2-x} \mathrm{Sr}_{x} \mathrm{Cu}_{1-y} \mathrm{Ru}_{y} \mathrm{O}_{4}$ compounds together with that of $\mathrm{Sr}_{4} \mathrm{Ru}_{2} \mathrm{O}_{9}$ as a $\mathrm{Ru}(\mathrm{V})$ reference. The $v(\mathrm{Ru})$ values indicate the $\mathrm{Ru}$ valence. The $\mathrm{Ru} \mathrm{L}_{2}$ data have been shifted and multiplied to overlap with the $\mathrm{Ru} \mathrm{L}_{3}$ data. For details, see text.

tures [both as regards the energy position and $\left.I\left(\mathrm{t}_{2 \mathrm{~g}}\right) / I\left(\mathrm{e}_{\mathrm{g}}\right)\right]$ being the same as those of the $\mathrm{Ru}(\mathrm{V})$ reference compound $\mathrm{Sr}_{4} \mathrm{Ru}_{2} \mathrm{O}_{9}$. In the foregoing, we have observed that the intensity ratio $I\left(\mathrm{t}_{2 \mathrm{~g}}\right) / I\left(\mathrm{e}_{\mathrm{g}}\right)$ in the $\mathrm{L}_{2}$ XAS spectra is the most sensitive spectral parameter to monitor an increase in $\mathrm{Ru}$ valence on going from $\mathrm{Ru}(\mathrm{IV})$ to $\mathrm{Ru}(\mathrm{V})$. This is a result of the larger intensity transfer from the $e_{\mathrm{g}}$-related to the $\mathrm{t}_{2 \mathrm{~g}}$-related peak in the $\mathrm{Ru} \mathrm{L_{2 }}$ XAS spectrum (as compared to the $\mathrm{Ru}-\mathrm{L}_{3}$ spectrum), which in turn is due to the differences in the intra-atomic interactions in the $\mathrm{Ru}(\mathrm{IV})\left[4 \mathrm{~d}^{4}\right]$ and $\mathrm{Ru}(\mathrm{V})\left[4 \mathrm{~d}^{3}\right]$ configurations, as shown in the theoretical spectra of Fig. 6. We stress that this spectral behavior is unexpected from crystal-field or mo- lecular-orbital theories of the $\mathrm{Ru} \mathrm{L}_{2,3} \mathrm{XAS}$, which predict the same ratio for the $\mathrm{L}_{2}$ and $\mathrm{L}_{3}$ spectra.

According the rules [Eqs. (1) and (2)] set up from the thermogravimetric measurements, sample $\mathrm{P}(1.36,0.2,0.28)$ lies in region (3) of the phase diagram shown in Fig. 1, and thus $v(\mathrm{Ru})$ should be greater than five. However, the experimental $\mathrm{Ru}$ $\mathrm{L}_{2,3}$ spectrum is identical with with that of sample $\mathrm{N}(1.28,0.4,0.04)$, which has $v(\mathrm{Ru})=5$, being at the border of regions (2) and (3) in the phase diagram. Inspection of Fig. 7 shows that sample $\mathrm{N}$ (and thus also $\mathrm{P}$ ) has a $\mathrm{Ru} \mathrm{L}_{2,3}$ spectrum essentially identical to that of the simple $\mathrm{Ru}(\mathrm{V})$ reference compound $\mathrm{Sr}_{4} \mathrm{Ru}_{2} \mathrm{O}_{9}$. In the case of sample $\mathrm{P}$ (formally with a valency greater than pentavalent), the charge balance is in fact achieved by the large oxygen deficit of $\delta=0.28$ and by a small number of holes located in the $\mathrm{CuO}_{6}$ octahedra, and seen in the $\mathrm{Cu} \mathrm{L}_{2,3}$ XAS spectra as a shoulder structure visible in Fig. 5. In both Figs. 6 and 7 one can see a narrowing of the both $t_{2 \mathrm{~g}}$ - and $\mathrm{e}_{\mathrm{g}}$-related peaks in the $\mathrm{Ru} \mathrm{L} \mathrm{L}_{2,3}$ edges as the $\mathrm{Ru}$ valence increases. The reason for this might be that $\mathrm{Cu}$ (II) and $\mathrm{Ru}(\mathrm{IV})$ are Jahn-Teller ions, causing distortions of the metal-oxygen octahedra of $6-7 \%$ and of $27 \%$ in $\mathrm{Sr}_{2} \mathrm{RuO}_{4}$ [10] and $\mathrm{La}_{2} \mathrm{CuO}_{4}$ [34], respectively. The Jahn-Teller related splitting of $\mathrm{e}_{\mathrm{g}}$ into $\mathrm{b}_{1 \mathrm{~g}}\left(\mathrm{~d}_{x}^{2}-\mathrm{d}_{y}^{2}\right)$ and $\mathrm{a}_{1 \mathrm{~g}}\left(\mathrm{~d}_{z}^{2}\right)$ as well as of $\mathrm{t}_{2 \mathrm{~g}}$ into $\mathrm{b}_{2 \mathrm{~g}}\left(\mathrm{~d}_{x y}\right)$ and $\mathrm{e}_{\mathrm{g}}\left(\mathrm{d}_{x z, y z}\right)$ is in fact too small to be experimentally resolved, and thus results only in an extra increase of the linewidth in $\mathrm{Sr}_{2} \mathrm{RuO}_{4}$. In $\mathrm{La}_{2-x} \mathrm{Sr}_{x}$ $\mathrm{Cu}_{1-y} \mathrm{Ru}_{y} \mathrm{O}_{4-\delta}$ a linear decrease of this distortion with increasing $\mathrm{Ru}$ valence is expected, since $\mathrm{Ru}(\mathrm{V})$ ions $\left(\mathrm{t}_{2 \mathrm{~g}}^{3}\right)$ exhibit no Jahn-Teller activity. In the case of $\mathbf{J}(2,0.7,0.1)$, we have found that $\mathrm{d}\left(\mathrm{B}-\mathrm{O}_{2}\right) / \mathrm{d}\left(\mathrm{B}-\mathrm{O}_{1}\right)$ is reduced to $1 \%$. In Fig. 8 we summarize the energy shifts of the $t_{2 g}$ - (filled circles) and $e_{\mathrm{g}}$-related (closed diamonds) features obtained from the $\mathrm{Ru} \mathrm{L} \mathrm{L}_{3}$ XAS spectra and the intensity ratio $I\left(\mathrm{t}_{2 \mathrm{~g}}\right) / I\left(\mathrm{e}_{\mathrm{g}}\right)$ (filled squares) from the $\mathrm{Ru} \mathrm{L}_{2}$ spectra as a function of $v(\mathrm{Ru})$. The open symbols show the values for the $\mathrm{Ru}(\mathrm{V})$ reference compound $\mathrm{Sr}_{4} \mathrm{Ru}_{2} \mathrm{O}_{9}$.

\section{4. $O K X A S$ spectra}

In general, in O K XAS spectra, the correlation effects are much weaker than in the TM $\mathrm{L}_{2,3}$ XAS 


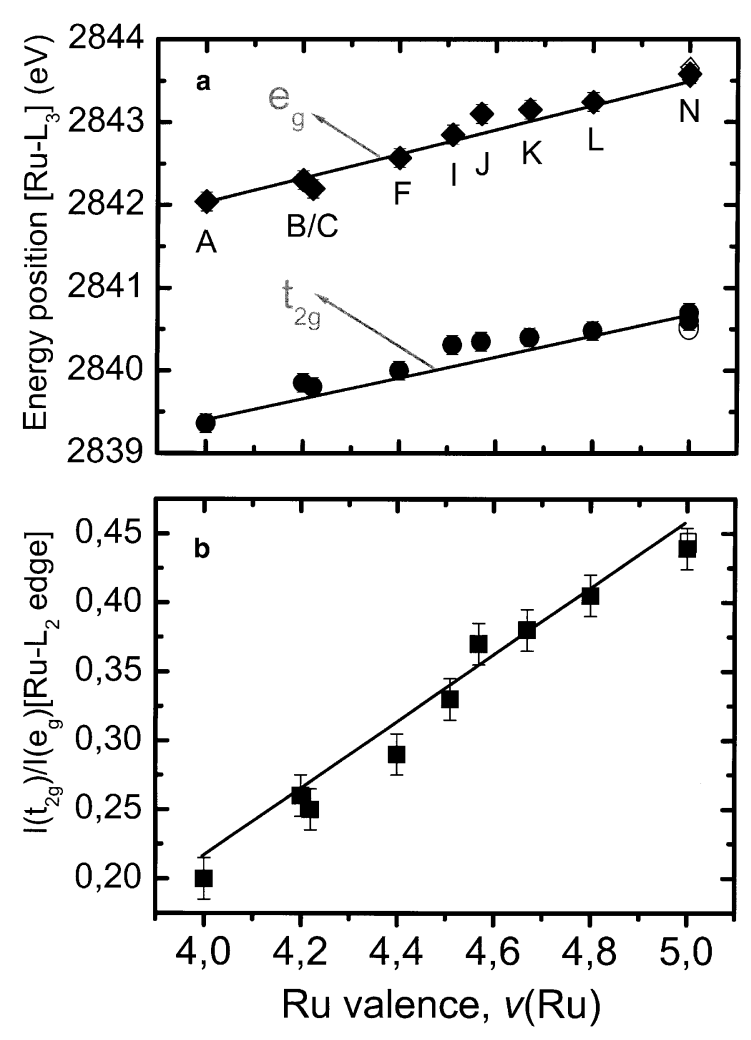

Fig. 8. (a) Energy positions of the $t_{2 \mathrm{~g}}$-related (filled circles) and the $\mathrm{e}_{\mathrm{g}}$-related (filled diamonds) features in the $\mathrm{Ru} \mathrm{L}_{3}$ XAS spectra and (b) intensity ratios $I\left(\mathrm{t}_{2 \mathrm{~g}}\right) / I\left(\mathrm{e}_{\mathrm{g}}\right)$ (filled squares) in the $\mathrm{Ru} \mathrm{L} \mathrm{L}_{2}$ XAS spectra of $\mathrm{La}_{2-x} \mathrm{Sr}_{x} \mathrm{Cu}_{1-y} \mathrm{Ru}_{y} \mathrm{O}_{4}$ as a function of $\mathrm{Ru}$ valence. The open symbols show data for the $\mathrm{Ru}(\mathrm{V})$ reference compound $\mathrm{Sr}_{4} \mathrm{Ru}_{2} \mathrm{O}_{9}$.

spectra, i.e., an agreement between the experimental spectra and the results of band structure calculations is plausible $[28,35,36]$. Therefore, $\mathrm{O} \mathrm{K}$ XAS spectra are usually studied in order to explore unoccupied states with $\mathrm{O} 2 \mathrm{p}$ character above $E_{\mathrm{F}}$ induced by covalence in the ground state, or by doping-induced hole occupancy of the $\mathrm{O} 2 \mathrm{p}$ states. The O K XAS spectra of $\mathrm{La}_{2-x} \mathrm{Sr}_{x} \mathrm{CuO}_{4}$ had been intensively studied previously both experimentally and theoretically in polarization-dependent measurements $[12,14,15]$. In Fig. 9 the single pre-edge peak in the undoped system $\mathrm{La}_{2} \mathrm{CuO}_{4}$ (a charge transfer insulator), can be identified with the upper Hubbard band (UHB) i.e., a transition into the empty state ofthe copper $3 \mathrm{~d}\left(x^{2}-y^{2}\right)$ orbitals which have an admixture of $\mathrm{O} 2 \mathrm{p}$ character. Upon

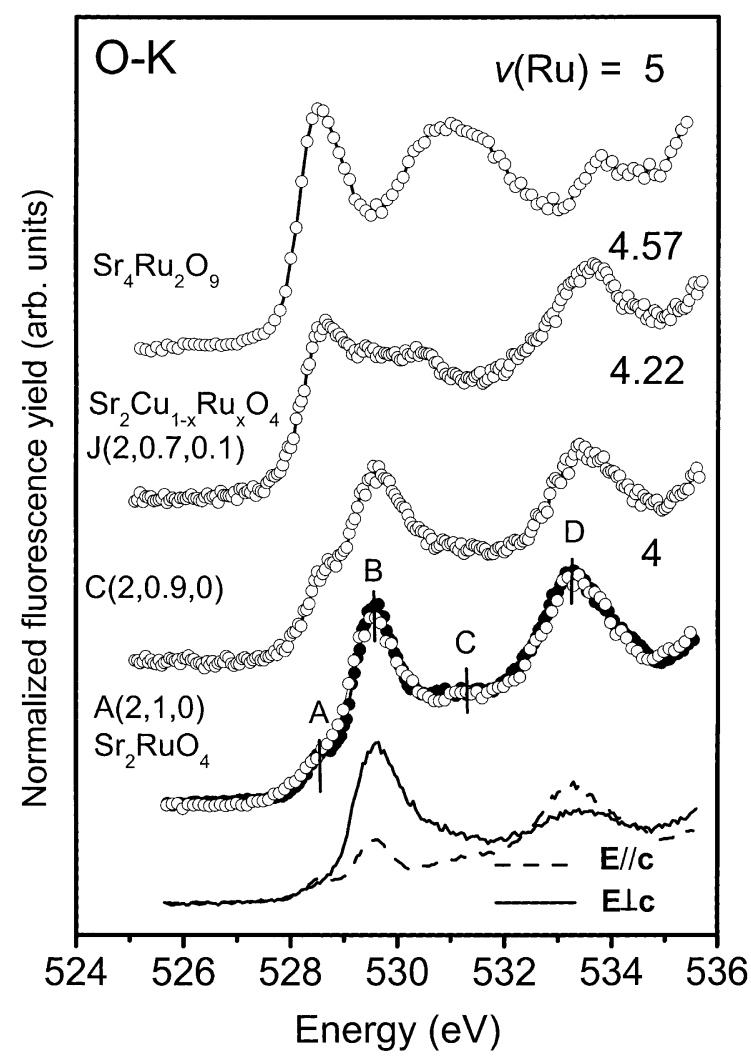

Fig. 9. O K XAS spectra of $\mathrm{Sr}_{2} \mathrm{Cu}_{1-y} \mathrm{Ru}_{y} \mathrm{O}_{4}$ with $\mathrm{Sr}_{4} \mathrm{Ru}_{2} \mathrm{O}_{9}$ as a $\mathrm{Ru}(\mathrm{V})$ reference.

doping, a new electronic state - the Zhang-Rice singlet (ZRS) occurs [37]. This feature is shifted by about $1.5 \mathrm{eV}$ to lower energy with respect to the UHB-related peak, and is often referred to as the doping hole state. From point view of the valence, it has already been mentioned that with increasing valence of the metal ion, the pre-edge peak is shifted to lower energy. In this work we concentrate on the O-K XAS spectral features from the $\mathrm{RuO}_{6}$ octahedra, where the doped holes are basically trapped.

Considering the splitting of the $t_{2 g}$ orbitals in the context of the Jahn-Teller and spin-orbit interactions, one would expect the $\Gamma_{8}^{1,2}$ and $\Gamma_{8}^{3,4}$ orbitals to be totally occupied and the $\Gamma_{7}^{1,2}$ orbital to be empty [18]. However, the $\mathrm{Ru} 4 \mathrm{~d}$ states are significantly more extended and more strongly hybridized than $\mathrm{Cu} 3 \mathrm{~d}$ states, leading to a larger band dispersion in the $\mathrm{Sr}_{2} \mathrm{RuO}_{4}$ [10]. The results of 
band structure calculations indicate that three bands cut $E_{\mathrm{F}}$, which falls on the low-energy side $(-0.06 \mathrm{eV})$ of a sharp peak arising from a van Hove singularity (VHS) in the electronic density of states (DOS) [10]. Two holes are found to reside in these bands. The TM-O hybridization results in open shell O 2porbitals leading to the low lying O $2 p$ unoccupied states detected in the O-K XAS spectra. The strong peak $\mathrm{B}$ in the $\mathrm{O} \mathrm{K}$ XAS spectra of $\mathrm{Sr}_{2} \mathrm{RuO}_{4}$ in Fig. 9 corresponds to the sharp VHS-related peak in the DOS. The data drawn using open circles are obtained from polycrystalline sample, while the data depicted using filled circles is an isotropic spectrum derived from polarization dependent spectra on the single crystal sample which are shown as solid and dashed lines below the data points for E//c and E//a, respectively. The structure near $E_{\mathrm{F}}$ is found in undoped $\mathrm{Sr}_{2} \mathrm{RuO}_{4}$ (called 'self-doping') and has predominantly $\mathrm{Ru} 4 \mathrm{~d}$ character mixed strongly with O $2 p$ [10]. The weak feature A had been assigned to apical $\mathrm{O}(2) 2 \mathrm{p}_{x}$, O $2 \mathrm{p}_{y}$ states hybridized with $\mathrm{Ru} 4 \mathrm{~d}_{x z}$ and $\mathrm{Ru} 4 \mathrm{~d}_{y z}$ [25]. According to the band structure calculations [10], the binding energy of $\mathrm{O}(2)$ is $1.5 \mathrm{eV}$ smaller than that for the in plane $\mathrm{O}(1)$. As stated above, generally, $4 \mathrm{~d}$ states are more delocalized than $3 \mathrm{~d}$ states, however, the $t_{2 g}$ states are much more localized than the $e_{g}$ states. The outcome of these competing tendencies is that the low-lying peak $\mathrm{B}$ in the $\mathrm{Sr}_{2} \mathrm{RuO}_{4}$ spectrum is not much different from the pre-edge peak in $\mathrm{La}_{2-x} \mathrm{Sr}_{x} \mathrm{CuO}_{4}$. The spectral weight from the $\mathrm{e}_{\mathrm{g}}-$ related states is low (see feature $\mathrm{C}$ ) and in the band structure calculations extends from $1-4 \mathrm{eV}$ above $E_{\mathrm{F}}[10,11]$. The $\mathrm{O} \mathrm{K}$ XAS spectra of $\mathrm{Sr}_{2} \mathrm{RuO}_{4}$ show better agreement with DOS obtained by Oguchi [11] than by Singh [10]. The overall spectral features are very similar to those obtained previously by Schmidt et al. [25]. However, in contrast to the analysis of [25] we wish to point out that structure $\mathrm{D}$ at $533.4 \mathrm{eV}$ mainly originates from $\mathrm{SrO}$ states. This assignment is supported by the spectrum of $\mathrm{Sr}_{4} \mathrm{Ru}_{2} \mathrm{O}_{9}$, in which the spectral feature from the $\mathrm{RuO}_{6}$ units is shifted by $1 \mathrm{eV}$ to lower energy upon increasing the $\mathrm{Ru}$ valence from $\mathrm{Ru}(\mathrm{IV})$ to $\mathrm{Ru}(\mathrm{V})$, which results in a better separation of the $\mathrm{RuO}_{6}$ related state from the $\mathrm{SrO}$ band. This shift to lower energy occurs in a manner fully analogous to the behavior observed in the spectra of 3d-TM oxides due to the increase of covalence with increasing valence [16,38]. Thus, the e $\mathrm{g}$-related peak in $\mathrm{Sr}_{4} \mathrm{Ru}_{2} \mathrm{O}_{9}$ is individually identifiable in the energy range $530.5-532.5 \mathrm{eV}$. It is evident that the lower energy $\mathrm{t}_{2 \mathrm{~g}}$-related peak at $528.5 \mathrm{eV}$ is narrower than the broad higher energy $e_{\mathrm{g}}$-related peak as already observed in the $\mathrm{Ru} \mathrm{L}_{2,3}$ XAS spectrum discussed earlier. This is a direct result of the stronger covalent $\operatorname{dp} \sigma$-like mixing between the $\mathrm{O}$ $2 \mathrm{p}$ and $\mathrm{Ru}-4 \mathrm{~d}\left(\mathrm{e}_{\mathrm{g}}\right)$ orbitals. $\mathrm{Ru}(\mathrm{V})$ with the $\mathrm{t}_{2 \mathrm{~g}}^{3} \mathrm{e}_{\mathrm{g}}^{0}$ configuration has been known to possess a high spin state $(S=3 / 2)$ and also shows antiferromagnetic spin order in $\mathrm{Ba}_{2} \mathrm{LaRuO}_{6}$ [38]. If holes were to be doped into both the $\mathrm{CuO}_{6}$ and $\mathrm{RuO}_{6}$ octahedra, the $\mathrm{O} \mathrm{K}$ XAS spectra of $\mathrm{La}_{2-x} \mathrm{Sr}_{x^{-}}$ $\mathrm{Cu}_{1-y} \mathrm{Ru}_{y} \mathrm{O}_{4-\delta}$ would be rather complicated as the UHB structure in $\mathrm{La}_{2} \mathrm{CuO}_{4}$ lies only $0.8 \mathrm{eV}$ above peak $\mathrm{B}$ in $\mathrm{Sr}_{2} \mathrm{RuO}_{4}$ and the $\mathrm{ZRS}$ structure originating from hole doping of the cuprate would strongly overlap with the first pre-edge peak in the $\mathrm{Ru}(\mathrm{V})$ oxides. Additionally, this superimposition would occur for both the in-plane and out-ofplane spectral structures in polarization-dependent data. However, if the doped holes are trapped only in the $\mathrm{RuO}_{6}$ octahedra, the $\mathrm{O} \mathrm{K}$ XAS spectra would then directly monitor the modification of the hole density interms of the growth of a low lying spectral feature arising solely from the $\mathrm{Ru}(\mathrm{V}) \mathrm{O}_{6}$ octahedra. Based upon these considerations, we discuss here only the $\mathrm{O} \mathrm{K}$ spectra of $\mathrm{Sr}_{2} \mathrm{Cu}_{1-x} \mathrm{Ru}_{x} \mathrm{O}_{4}$, since the UHB feature from the $\mathrm{Cu}(\mathrm{II}) \mathrm{O}_{6}$ octahedra lies a comfortable $1.8 \mathrm{eV}$ above the $\mathrm{Ru} 4 \mathrm{~d} \mathrm{t}_{2 \mathrm{~g}}$-related feature from the $\mathrm{Ru}(\mathrm{V}) \mathrm{O}_{6}$ octahedra. The $\mathrm{O} \mathrm{K}$ spectra of $\mathrm{Sr}_{2} \mathrm{Cu}_{1-y}$ $\mathrm{Ru}_{y} \mathrm{O}_{4-\delta}$ are shown in Fig. 9. The spectrum of sample $\mathrm{C}[v(\mathrm{Ru})=4.22]$ exhibits a low-energy shoulder visible below the main $\mathrm{Ru}(\mathrm{IV}) \mathrm{t}_{2 \mathrm{~g}}$-related feature. This shoulder lies at the same energy as the first pre-edge peak in $\mathrm{Sr}_{2} \mathrm{Ru}_{2} \mathrm{O}_{9}$ and thus is assigned to holes in $\mathrm{t}_{2 \mathrm{~g}}$ states in $\mathrm{Ru}(\mathrm{V}) \mathrm{O}_{6}$ octahedra. On further increasing the $v(\mathrm{Ru})$ to 4.57 (sample $\mathrm{J}$ ) the $\mathrm{Ru}(\mathrm{V}) \mathrm{t}_{2 \mathrm{~g}}$-features becomes dominant and the $\mathrm{Ru}(\mathrm{IV}) \mathrm{t}_{2 \mathrm{~g}}$-related structure overlaps partly with the UHB from the $\mathrm{Cu}(\mathrm{II}) \mathrm{O}_{6}$ octahedra and is thus no longer resolvable as a separate peak. From Fig. 9 we can conclude that with increasing $\mathrm{Cu}$ concentration in $\mathrm{Sr}_{2} \mathrm{Cu}_{1-y} \mathrm{Ru}_{y} \mathrm{O}_{4}$ the $\mathrm{Ru}$ 
valence increases, as was proven earlier in the context of the $\mathrm{Ru} \mathrm{L} \mathrm{L}_{2,3}$ XAS spectra. This leads, then, to the creation of high spin $S=3 / 2 \mathrm{Ru}(\mathrm{V})$ ions, which if considered as 'impurities' will not be beneficial for superconductivity.

\section{Summary}

From a systematic study of the $\mathrm{Cu} \mathrm{L}_{2,3}$, $\mathrm{Ru} \mathrm{L}_{2,3}$, and $\mathrm{O} \mathrm{K}$ XAS spectra of the system $\mathrm{La}_{2-x} \mathrm{Sr}_{x} \mathrm{Cu}_{1-y} \mathrm{Ru}_{y} \mathrm{O}_{4-\delta}$ combining both experiment and theory, we have found that for $x>2 y$, the charge balance upon $\mathrm{Sr}$ and $\mathrm{Ru}$ doping is achieved by an increase of the $\mathrm{Ru}$ valence from $\mathrm{Ru}(\mathrm{IV})$ to $\mathrm{Ru}(\mathrm{V})$ when going from region (1) to region (3) [via region (2)] of the phase diagram shown in Fig. 1, with a pure $\mathrm{Ru}(\mathrm{V})$ valence being reached at the border between regions (2) and (3). At all stages the $\mathrm{Cu}$ remains essentially divalent. In region (3) of the phase diagram, $\mathrm{Ru}$ remains as $\mathrm{Ru}(\mathrm{V})$, and charge balance requirements lead to an oxygen deficit $\delta$ and a transfer of holes into the $\mathrm{CuO}_{6}$ octahedra, before leading finally to a breakdown of the $\mathrm{K}_{2} \mathrm{NiF}_{4}$-type structure at high $\delta$. Although hole counts of up to 0.2 holes per $\mathrm{CuO}_{6}$ octahedra can be reached in region (3), these systems are not superconductors. By comparison with data from band structure calculations, we have found that the O K XAS spectra exhibit a larger unoccupied DOS just above $E_{\mathrm{F}}$ in undoped $\mathrm{Sr}_{2} \mathrm{RuO}_{4}$ than is the case in over-doped $\mathrm{La}_{2-x} \mathrm{Sr}_{x} \mathrm{CuO}_{4}$. The doped holes in the $\mathrm{Ru}(\mathrm{V}) \mathrm{O}_{6}$ octahetra are reflected by the appearance of lower energy structure in the O K XAS spectra by comparison with a simple $\mathrm{Ru}(\mathrm{V})$ reference compound.

The lower Coulomb repulsion energy $\mathrm{U}$ for $\mathrm{Ru}$ than for $\mathrm{Cu}$ makes $\mathrm{Ru}$ valence fluctuations significantly more favourable in the $4 \mathrm{~d}$ electron system, resulting in $\mathrm{Ru}(\mathrm{IV}) \rightarrow \mathrm{Ru}(\mathrm{V})$ transitions upon hole doping. The introduction of these high-spin $\mathrm{Ru}(\mathrm{V})$ $(S=3 / 2)$ centers most likely brings with it a strong impurity effect in the mixed $(\mathrm{Cu}, \mathrm{Ru}) \mathrm{O}_{2}$ planes, which is not beneficial for superconductivity. Indeed, analysis of the electrical resistivity indicate that the presence of $\mathrm{Cu}-\mathrm{O}-\mathrm{Ru}-\mathrm{O}-\mathrm{Cu}$ interaction pathways mainly suppresses conductivity.

\section{Acknowledgements}

We thank F. Grasset and J. Darriet for providing the $\mathrm{Sr}_{4} \mathrm{Ru}_{2} \mathrm{O}_{9}$ sample and the staff of BESSY and HASYLAB for experimental assistance. This work was supported in part by the Deutsche Forshungsgemeinschaft within SFB 463, SFB 484, and SFB 608.

\section{References}

[1] J.G. Bednorz, K.A. Müller, Z. Phys. B 64 (1986) 189.

[2] K. Sreedhar, C.N.R. Rao, Mater. Res. Bull. 25 (1990) 1235.

[3] Y. Maeno, H. Hashida, K. Yoshida, S. Nishizaki, T. Fujita, G. Bednorz, F. Lichtenberg, Nature (London) 372 (1994) 32.

[4] K. Ramesha, S. Uma, N.Y. Vasanthacharya, J. Gopalakrishnan, J. Solid State Chem. 128 (1997) 169.

[5] M.P. Attfield, P.D. Battle, S.K. Bollen, S.H. Kim, A.V. Powell, M. Workman, J. Solid State Chem. 96 (1992) 344.

[6] S.H. Kim, P.D. Battle, J. Magn. Magn. Mater. 123 (1993) 273.

[7] S. Ebbinghaus, A. Reller, Solid State Ionics 101-1031 (1997) 369.

[8] S. Ebbinghaus, M. Fröba, A. Reller, J. Phys. Chem. B 101 (1997) 99099.

[9] J. Zaanen, G.A. Sawatzky, J.W. Allen, Phys. Rev. Lett. 55 (1985) 418.

[10] D.J. Singh, Phys. Rev. B 52 (1995) 1358.

[11] T. Oguchi, Phys. Rev. B 51 (1995) 1385.

[12] see e.g. J. Fink, N. Nücker, E. Pellegrin, H. Romberg, M. Alexander, M. Knupfer, J. Electron Spectrosc. Relat. Phenom. 66 (1994) 395

[13] Z. Hu, C. Mazumdar, G. Kaindl, F.M.F. de Groot, S.A. Warda, D. Reinen, Chem. Phys. Lett. 297 (1998) 321.

[14] C.T. Chen, L.H. Tjeng, J. Kwo, H.L. Kao, P. Rudolf, F. Sette, R.M. Fleming, Phys. Rev. Lett. 68 (1992) 2543.

[15] C.T. Chen, F. Sette, Y. Ma, M.S. Hybertsen, E.B. Stechel, W.M.C. Foulkes, M. Schulter, S.-W. Cheong, A.S. Cooper, L.W. Rupp Jr., B. Batlogg, Y.L. Soo, Z.H. Ming, A. Krol, Y.H. Kao, Phys. Rev. Lett. 66 (1991) 104.

[16] Z. Hu, G. Kaindl, S.A. Warda, D. Reinen, F.M.F. de Groot, B.G. Müller, J. Chem. Phys. 101 (1994) 6570.

[17] G. Kaindl, O. Strebel, O. Kolodziejczky, A. Schäfers, W. Kiems, R. Lösch, S. Kemmler-Sack, R. Hoppe, H.P. Müller, D. Kissel, Physica B 158 (1989) 446.

[18] Z. Hu, H. von Lips, M.S. Golden, J. Fink, G. Kaindl, F.M.F. de Groot, S. Ebbinghaus, A. Reller, Phys. Rev. B $61(2000) 5262$.

[19] C. Dussarrat, J. Formpeyrine, J. Darriet, Eur. J. Solid State Chem. 32 (1995) 3.

[20] L. Tröger, D. Arvanitis, K. Baberschke, H. Michaelis, U. Grimm, E. Zschech, Phys. Rev. B 46 (1992) 3283. 
[21] J. Jaklevic, J.A. Kirby, M.P. Klein, A.S. Robertson, Solid State Commun. 23 (1997) 679.

[22] K. Okada, A. Kotani, J. Phys. Soc. Jpn. 68 (1999) 666.

[23] M.S. Golden, C. Dürr, A. Koitzsch, S. Legner, Z. Hu, S. Borisenko, M. Knupfer, J. Fink, J. Electron Spectrosc. Relat. Phenom. 117 (2001) 203.

[24] S. Ebbinghaus, Z. Hu, A. Reller, J. Solid State Chem. 156 (2001) 194.

[25] M. Schmidt, T.R. Cummins, M. Bürk, D.H. Lu, N. Nücker, S. Schuppler, F. Lichtenburg, Phys. Rev. B 53 (1996) R14761.

[26] R.J. Cava, B. Batlogg, K. Kiyono, H. Takagi, J.J. Krajewski, W.F. Peck Jr., L.W. Rupp Jr., C.H. Chen, Phys. Rev. B 49 (1994) 1890.

[27] A. Fujimori, H. Namatame, K. Akeyama, N. Kosugi, Phys. Rev. B 49 (1994) 7193.

[28] F.M.F. de Groot, Doctoral Thesis, Katholieke Universitet Nijmegen, 1991.

[29] C. Sugiura, M. Kitamura, S. Muramatsu, J. Chem. Phys. 84 (1986) 4824.
[30] G.N. George, W.E. Cleland Jr., J.H. Enemark, B.E. Smith, C.A. Kipke, S.A. Roberts, S.P. Cramer, J. Am. Chem. Soc. 112 (1990) 2541.

[31] C. Sugiura, M. Kitamura, S. Muramatsu, J. Phys. Chem. Solids 49 (1988) 1095.

[32] T.K. Sham, J. Am. Chem. Soc. 105 (1983) 2269.

[33] F.M.F. de Groot, Z. Hu, M.F. Lopez, G. Kaindl, F. Guillot, M. Tronic, J. Chem. Phys. 101 (1994) 6570 .

[34] V.B. Grande, H. Müller-Buschbaum, M. Schweizer, Z. Anorg. Chem. 428 (1977).

[35] M. Abbate, R. Potze, G.A. Sawatzky, A. Fujimori, Phys. Rev. B 49 (1994) 7210.

[36] A. Fujimori, I. Hase, M. Nakamura, H. Namatame, Y. Fujishima, Y. Tokura, Abbate, F.M.F. de Groot, M.T. Czyzyk, J.C. Fuggle, O. Strebel, F. Lopez, M. Domke, G. Kaindl, Phys. Rev. B 46 (1992) 9841.

[37] F.C. Zhang, T.M. Rice, Phys. Rev. B 37 (1994) 330.

[38] P.D. Battle, J.B. Goodenough, R. Paice, J. Solid State Chem. 46 (1983) 234. 